\title{
RETROPERITONEAL LEIOMYOSARCOMA: A CASE REPORT
}

\author{
BANU NA ${ }^{1}$, AKTER SH${ }^{2}$, TALUKDAR RR ${ }^{3}$, BANU NA $^{4}$, ISLAM NI ${ }^{5}$
}

\begin{abstract}
:
Leiomyosarcoma is the second most common (10\% to 37\%) primary retroperitoneal tumour in adults. It is a rare malignant tumour originating from smooth muscle. Soft tissue sarcomas include a heterogeneous group of neoplasms of different histologies and comprise less than one percent of all adult malignancies. About 10\% to $20 \%$ soft tissue sarcoma arises from retroperitoneum. Retroperitoneal leiomyosarcoma is not associated with any specific sign and symptoms. They often reach a very large size before the diagnosis is made. They may present with vague generalized symptoms such as weakness, weight loss, abdominal pain discomfort or pain. Sometimes they present with a painless palpable mass in abdomen. Diagnosis is confirmed by examination of the tissue obtained by biopsy. Due to advanced stage of the lesion at the time of presentation, treatment is difficult and results are usually unsatisfactory. Treatment of choice is surgical excision with a clear margin, which is frequently impossible due to invasion of the tumor to surrounding structures. Prognosis is related with extent of invasion and adequacy of excision. Although radiation and adjuvant chemotherapy has been used in some cases, the prognosis for this lesion remains poor. Most patients die of local recurrence or distant metastasis. A 38 year old female patient with retroperitoneal leiomyosarcoma has been reported here. The patient was admitted into Obstetrics and Gynaecology Department of Bangladesh Medical College Hospital on 17.07.2010 as a case of pelvic mass of uncertain origin. Diagnosis of leiomyosarcoma was confirmed by histopathology and immunohistochemistry of the pelvic mass removed by laparotomy.
\end{abstract}

Key words: Leiomyosarcoma, malignant tumour, pelvic mass.

J Dhaka Med Coll. 2012; 21(2) : 229-234.

\section{Introduction:}

Sarcomas are malignant tumors arising from mesenchymal cell lines. Leiomyosarcoma is an aggressive soft tissue sarcoma derived from smooth muscle cells typically of uterine, gastrointestinal or soft tissue origin. Leiomyosarcoma consists of $5 \%$ to $10 \%$ of all soft tissue sarcoma. ${ }^{1} 10 \%$ to $20 \%$ of soft tissue sarcomas occur in the retroperitoneum. ${ }^{2-6}$ In a population based series reported in the Surveillance, Epidemiology and End Results (SEER) database, the average annual incidence of retroperitoneal sarcoma was approximately 2.7 cases per million populations ${ }^{7}$. Leiomyosarcoma is more common in women (2:1 ratio) and usually occur in $5^{\text {th }}$ and $7^{\text {th }}$ decades of life. ${ }^{2-5}$ This gender distribution may reflect the proliferation of smooth muscle that can occur in response to estrogen. They occur most commonly (50\%) in the retroperitoneum. ${ }^{8}$ Leiomyosarcoma typically affects adults, however they can present in childhood. ${ }^{9-11}$ Leiomyosarcoma of soft tissue is thought to arise from smooth muscle cells lining small blood vessels. These tumors are often difficult to treat with survival rates among the lowest of all soft tissue sarcomas. ${ }^{12}$ Plain radiographs of the affected area, computed tomography and magnetic resonance imaging should be included in initial investigations. Angiography may be useful in cases involving major blood

1. Dr. Nasima Arjumand Banu, Assistant Professor, Department of Obstetrics and Gynaecology, Bangladesh Medical College, Dhaka.

2. Dr. Sayeda Husna Akter, Senior Consultant, Department of Obstetrics and Gynaecology, Bangladesh Medical College Hospital, Dhaka.

3. Dr. Rezaur Rahman Talukdar, Associate Professor, Department of Surgery, Bangladesh Medical College, Dhaka.

4. Dr. Nahida Arjumand Banu, Consultant in Histopathology, Department of Cellular Pathology, Southmead Hospital, Bristol, United Kingdom.

5. Dr. Nasim Imtiaz Islam, Honorary Medical Officer, Department of Medicine, Dhaka Medical College Hospital, Dhaka. Correspondence: Dr. Nasima Arjumand Banu, Assistant Professor, Department of Obstetrics and Gynaecology, Bangladesh Medical College, Dhanmondi, Dhaka-1209. E-mail: nasima.banu28@gmail.com 
vessels. A specific diagnosis of leiomyosarcoma may be established by performing a $\mathrm{CT}$ guided core needle biopsy. The presenting symptoms include abdominal discomfort, abdominal mass and/ or weight loss. The retroperitoneum provides a widely expansible anatomic location for tumors arising there, and these tumors often become very large before the symptoms appear. ${ }^{6}$ The median size at diagnosis is approximately $15 \mathrm{~cm} .{ }^{13}$ The definitive histological diagnosis of leiomyosarcoma is difficult because of the similarity with other spindle cell sarcomas ${ }^{14}$. The immunohistochemical analysis for cytoesqueletal proteins such as actin, vimentin, desmin, cytokeratin (CK), muscle specific antigen (HHF35), epithelial membrane antigen (EMA) and ultra structural examination has been widely used for the diagnosis of leiomyosarcoma. ${ }^{15}$ Retroperitoneal leiomyosarcoma is a highly malignant disease that is often not amenable to complete surgical resection. Prognosis is poor, with a high rate of recurrence or metastasis. Lungs, bone, brain and the lymph nodes are the most common sites of metastasis. $^{2-6}$

\section{Case Report:}

A 38 year old married woman was admitted into Obstetrics and Gynaecology Department of Bangladesh Medical College Hospital, Dhaka in $17^{\text {th }}$ July, 2010 with history of a palpable painless abdominal mass for last three months which was gradually increasing in size. Physical examination revealed a non-tender smooth surfaced mass of about $15 \mathrm{~cm}$ over the left middle portion of the abdomen. On pelvic examination, the mass is separated from the uterus, occupying the whole pelvis and was pushing the uterus anteriorly. Another cystic, non-tender mass of about $6 \mathrm{~cm}$ was felt through left fornix. The patient had history of laparotomy followed by right sided salpingo-oophorectomy one year back for right sided ovarian tumor. Histopathological diagnosis of that tumor was benign mesenchymal fibroma. On 17.07.2010, her ultrasonography of whole abdomen was done. An irregular complex mass measuring about $142 \mathrm{~mm} \times 93 \mathrm{~mm}$ was noted in right side of pelvic cavity. Another cystic area measuring about $65 \mathrm{~mm} \times 50 \mathrm{~mm}$ was also noted in left adnexal region. Her intravenous urography was done on 19.07.2010. It was suggestive of large pelvic mass with mild pressure effect over the both lower ureters and right kidney. Both kidneys were normal in excretion. X-ray of lumbosacral region showed early lumber osteoarthritis with lumber spondylosis. The patient was not anaemic. Her serum CA-125 was $37.8 \mathrm{IU} / \mathrm{mL}$, total serum protein $61 \mathrm{gm} / \mathrm{L}$ and albumin $30 \mathrm{gm} / \mathrm{L}$. Ultrasound guided FNAC was done and the result was compatible with benign mesenchymal fibroma.

Her laparotomy was done on 22.07.2010. Per operatively, uterus was normal in size. Left fallopian tube healthy but left ovary was cystic, containing serous fluid. Right ovary and fallopian tube were absent due to previous surgical removal.

A well circumscribed, firm, fleshy, grey-white retroperitoneal mass was found to occupy the whole pelvis. It was compressing the rectum, from which the tumor had to be scraped off. Total abdominal hysterectomy with left sided salpingo-oophorectomy was done. The main bulk of the pelvic mass was removed after gentle dissection. But complete removal was not possible due to increased friability, bleeding and invasion of surrounding structures. Colostomy was done. Three units of whole blood were transfused during and after operation.

Histopathological examination of retroperitoneal mass revealed a cellular mesenchymal tumor, composed of spindle cells, arranged in interlacing fascicles. The tumor was highly cellular but significant pleomorphism was not seen. Mitotic figures were seen in small numbers. No necrosis was seen. Features were suggestive of low grade fibrosarcoma.

Her CT scan of whole abdomen was done postoperatively on 01.08.2010. A fairly large isodense soft tissue mass lesion was seen in the central lower posterior pelvic cavity. After IV contrast, heterogeneous enhancement of the lesion was noted. The lesion was partly adherent to the urinary bladder. Pelvic fat planes were distorted mainly on the right side. The CT scan findings were suggestive of rectal growth/? GIST. 
Later, the same specimen was reviewed again and the histopathological diagnosis was spindle cell tumor composed of cells with vesicular nuclei and eosinophilic cytoplasm. The spindle cells were arranged in fascicles. The cells had small but prominent nucleoli and showed mild nuclear pleomorphism. Immunohistochemisty was carried out but was not very helpful due to processing artifact. Only vimentin stain was strongly positive, whereas SMA, desmin, HMB 45 and S100 appeared non-specific. Although immunohistochemistry was not of much use, the morphological features are suggestive of a leiomyosarcoma.

The patient was stable when discharged on her $10^{\text {th }}$ postoperative day. But she died of recurrence of the disease six months later.

\section{Discussion:}

Leiomyosarcoma are rare tumours that may arise from any smooth muscle source. Retroperitoneal leiomyosarcoma occurs most commonly in the $5^{\text {th }}$ to $7^{\text {th }}$ decade and are more common in females. The age of our female patient (38 years) is not consistent with previous reports. Retroperitoneal tumours typically have vague presenting symptoms. Like other sarcomas, radiographic imaging findings are non-specific. These tumours are provided with a well concealed, widely expansible area, leading to the development of large masses with local and distant metastases before the patient become symptomatic. Todd et al. ${ }^{6}$ reported that the most common clinical picture of retroperitoneal sarcoma cases at presentation includes back pain and weight loss $(37.5 \%)$ with fatigue $(25 \%)$. Increased abdominal girth $(12.5 \%)$ and fever or night sweats $(12.5 \%)$ are also noted. These patients exhibited symptoms for an average 3.5 months before presentation. Cody et al. ${ }^{3}$ and Braasch et al. ${ }^{16}$ reported abdominal pain and weight loss as the most common symptoms.

Staging of leiomysosarcoma is important both in guiding treatment and in providing prognostic information. The most commonly used system is the American Joint Committee on Cancer (AJCC) system. ${ }^{17}$ This system classifies the tumor based upon histological grade, tumor size, location at superficial or deep and the presence or absence of metastasis.

The surgical Staging System of the Musculoskeletal Tumor Society (MSTS) is also used. It is utilized for staging bone and soft tissue sarcoma, including leiomyosarcoma. ${ }^{18}$ This staging system classifies tumors as Ia, Ib, IIa, IIb or III based upon the histological grade of the tumor, its local extent and the presence or absence of macroscopic distant metastasis.

Typical histological features of leiomyosarcoma include a highly cellular field, with abundant pink to deep red cytoplasm on H\&E staining. The cells are arranged in fascicles. The nuclei are usually central and are classically described as cigar-shaped. One of the key features is the presence of myofibrils that are longitudinal and run the length of the cell. ${ }^{14,19-22}$ In some cases nuclear hyperchromasia and pleomorphism is present. One to twenty mitoses per high power field may be observed. ${ }^{20,23}$ Histological feature under light microscopy are the most important factors in making the diagnosis of leiomyosarcoma. However, immunohistochemistry and electron microscopy play an important confirmatory role. ${ }^{24}$ Immunohistochemistry helps support the diagnosis by demonstrating the presence of muscle specific markers including desmin, vimentin, muscle specific antigen (HHF 35), cytokeratin (CK) and epithelial membrane antigen (EMA). While not required to make the diagnosis, one or more of these markers is usually found in specimens of leiomyosarcoma. ${ }^{15,25-27}$ Electron microscopy is useful in further elucidating the classic nuclear morphology seen in this tumor. Cytogenetic analysis in leiomyosarcoma has not shown a consistent chromosomal aberration or translocation. ${ }^{28}$ Size, cellularity, atypia, necrosis and mitoses per high power field are characteristics that differentiate between benign smooth muscle tumor and leiomyosarcoma. Of these points, mitoses per high power field is considered the most reliable. ${ }^{29}$

Leiomyosarcoma is a chemotherapy and radiation resistant malignancy. Surgery is the 
treatment of choice, followed by other ablative method. Surgery is the main treatment factor in the outcome of retroperitoneal leiomyosarcoma. ${ }^{14,30-32}$ Complete surgical resection with at least $3 \mathrm{~cm}$ margins is the ideal treatment, but is rarely feasible due to invasion of surrounding structures by the tumour. ${ }^{6,33,34}$ Erzen et al. ${ }^{31}$ pointed out that some tumors might need to be resented en bloc with adjacent structures in order to obtain free margins. The most frequent organ resected was bowel. Curative surgery is difficult with large retroperitoneal sarcomas and those in close proximity to vital structures and involving adjacent organs. (30) The rate of complete resection has varied in the literature from 38\% to $95 \% .^{3,4,32,33}$

Liposarcoma, leiomyosarcoma and malignant fibrous histiocytoma represented $66 \%$ of the tumours in Stoeckle et al.'s review ${ }^{14}$ of 165 cases of retroperitoneal sarcoma. Complete excision was achieved in 94 of 145 patients who had no metastasis. The overall 5 year survival rate was $46 \%$. The main prognosis factors for survival were initial metastasis and surgery. ${ }^{14}$ In the present case, the major bulk of the tumor was removed but clear margin could not be achieved due to invasion to surrounding structures. The patient has been followed up up to six months till she died of recurrence and distant metastasis.

Low grade tumours independent of the histologic type exhibited good prognosis for long term survival with a median survival of 44 months. In contrast, intermediate or high grade tumors were associated with a median survival rate of only 9 months. Leiomyosarcoma was associated with a median survival time of 24 months. ${ }^{14,35,36}$ According to Stockle et al. ${ }^{14}$ $84 \%$ of the tumors of total 165 cases were of high or intermediate grade. There was no significant survival difference between different histological type tumours. A high grade affected local recurrence, metastatic recurrence and survival. ${ }^{14}$

There are few studies with evidence of effective radiotherapy for retroperitoneal leiomyosarcoma. In non-randomized retrospective series, the addition of adjuvant radiotherapy after surgical resection is associated with a reduced risk of local recurrence and a longer recurrence-free interval, but there has generally been no suggestion of an impact on survival. ${ }^{5,14,35-37}$ Svarvar et al. ${ }^{40}$ reviewed 225 patients with non-visceral soft tissue leiomyosarcomas, and there was no significant difference between complete surgical resection with or without adjuvant radiotherapy in the long term prognosis. Multivariate analysis of the cases showed that a higher grade malignancy, large tumors and deep tumors were correlated with decreased metastatic free survival. Inadequate local treatment was associated with local recurrence and a high degree of malignancy was associated with decreased overall survival.

With the exception of childhood soft tissue sarcomas such as rhabdomyosarcoma and extraskeletal Ewing's sarcoma, the benefits of adjuvant chemotherapy for soft tissue sarcoma remain controversial. ${ }^{41,42}$ The use of adjuvant chemotherapy following surgical resection of retroperitoneal leiomyosarcoma is not a standard approach. ${ }^{6,43}$ Currently, however, in general local control in obtained with wide surgical excision. Neoadjuvant or adjuvant radiation therapy is appropriate in some circumstances where local control is an issue. Chemotherapy is employed for the treatment of systemic disease. Ongoing clinical trials may identify agents that may improve the overall and disease-free survival of patients.

\section{Conclusion:}

Leiomyosarcoma is a vicious sarcoma that can occur in many different locations. Though advances have been made in treatment protocols, leiomyosarcoma remains one of the most difficult soft tissue sarcoma to treat. Correct diagnosis, classification and multi modality treatment by physicians who are familiar with these tumours are essential to favourable outcome. We should emphasize the importance of an early diagnosis on survival of the patient. This diagnosis can only be achieved if a representative fragment of the lesion is obtained. In addition, immunohistochemistry was very important to establish a final diagnosis of leiomyosarcoma. 


\section{Acknowledgement:}

We thank Mr. Ishtiaq Rabiul Islam for his help in the preparation of this article.

\section{References:}

1. Gustafson P, Willen H, Baldtrop B, et al. Soft tissue leiomyosarcoma: a population based epidemiologic and prognostic study of 48 patients, including cellular DNA content. Cancer 1992; 70: 114.

2. Adam Y, Osland J, Harvey A, Reif R. Primary retroperitoneal soft tissue sarcoma. J Surg Oncol 1984; 25: 8-11.

3. Cody HS, Turnball AD, Fortner JG, Haj-du SI. The continuing challenge of retroperitoneal sarcomas. Cancer 1981; 47: 2147-52.

4. McGrath P, Neifeld JP, Lawrence W, DeMay RM, Kay S, Horsley JS, et al. Improved survival following complete excision of retroperitoneal sarcomas. Ann Surg 1984; 200: 200-4.

5. Catton CN, O'Sullivan B, Kotwall C, Cummings B, Hao Y, Fornasier V. Outcome and prognosis in retroperitoneal soft tissue sarcoma. Int $\mathrm{J}$ Radia Oncol 1994; 29: 1005-10.

6. Todd CS, Michael H, Sutton G. Retroperitoneal leiomyosarcoa: eight cases and a literature review. Gynecol Oncol 1995; 59: 333-7.

7. Dalal KM, Kattan MW, Antonescu CR, Brennan $\mathrm{MF}$, Singer S. Subtype specific prognostic nomograms for patients with primary liposarcoma of the primary liposarcoma of the retroperitoneum, extremity or trunk. Ann Surg 2006; 244: 381-9.

8. Golden T, Stout AP. Smooth muscle tumor of the gastrointestinal tract and retroperitoneal tissue. Surg Gynecol Obstet 1941; 73: 784.

9. Lack EE. Leiomyosarcoma in childhood: a clinical and pathologic study of 10 cases. Pediatr Pathol 1986; 6: 181.

10. Yannopoulos K, Stout AP. Smooth muscle tumors in children. Cancer 1962; 15: 952.

11. De Saint Aubain Somerhausen N, Fletcher C. Leiomyosarcomas of soft tissue in children: clinicopathologic analysis of 20 cases. Am J Surg Pathol 1999; 23(7): 755.

12. Mankin HJ, Casas Ganem J, Kim JL, et al, Leiomyosarcoma of somatic soft tissues. Clin Orthop Relat Res 2004; 421: 225-31.

13. Stoeckle E, Coindre JM, Bonvalst S, Kantor G, Terrier P, Bonichon F, et al. Prognostic factors in retroperitoneal sarcoma: a multi-variate analysis of a series of 165 patients of the French Cancer Center Federation Sarcoma Group. Cancer 2001; 92: 359-68.
14. Enzinger FM, Weiss SW. Soft tissue tumors. St Louis: Mosby; 1995: p. 491-510.

15. Izumi K, Maeda T, Cheng J, Saku T. Primary leiomyosarcoma of the maxilla with regional lymph node metastasis: report of a case and review of the literature. Oral Surg Oral Med Oral Pathol Oral Radiol Endod 1995; 80: 310.

16. Braasch JM, Mon AB. Primary retroperitoneal tumors. Surg Clin North Am 1967; 47: 663-77.

17. Fleming ID, Cooper JS, Henson DE, et al, AJCC Cancer Staging Manual. 1997; 5.

18. Enneking WF, Spanier SS, Goodman MA. A system for the surgical staging of musculoskeletal sarcoma. Clin Orthopaed Related Res 1980; 153: 106-20.

19. Weiss SW, Goldblum JR. ed. Enzinger and Weiss's soft tissue tumors. St. Louis: Mosby; 2001: p. 4.

20. Bass B, Archard H, Sussman R, Stern M, Saunders V. Clinicopathologic conferences: case 62: expansible radiolucent lesions of the mandible. J Oral Maxillofac Surg 1986; 44: 799-803.

21. Allen CM, Neville B, Damm DD, Marsh W. Leiomyosarcoma metastatic to oral region: report of three cases. Oral Med Oral Pathol 1993; 76: 752-6.

22. Kratochvil FJ, MacGregor SD, Budnick SD, Hewan-Lowe K, Allsup H. Leiomyosarcoma of the maxilla: report of a case and review of the literature. Oral Surg Oral Med Oral Pathol 1982; 54: 647-55.

23. Poon CK, Kwan PC, Yin NT. Leiomyosarcoma of gingiva: report of case and review of the literature. J Oral Maxillofac Surg 1987; 45: 888-92.

24. Lack EE. Primary leiomyosarcoma of adrenal gland: case report with immunohistochemical and ultrastructural study. Am J Surg Pathol 1991; 15: 899-905.

25. Lo Muzio L, Fazia G, Mimgnogna MD, Piattelli A, Maiorano E. Primary intra oral leiomyosarcoma of the tongue: an immunohistochemical study and review of the literature. Oral Oncol 2000; 36: 51924.

26. Mesquita RA, Migliari DA, De Souza SOM, Alves MR. Leiomyosarcoma of the buccal mucosa: a case report. J Oral Maxillofac Surg 1998; 56: 504-7.

27. Watanabe K, Kusakabe T, Hoshi N, Saito A, Suzuki T. h-Caldesmen in leiomyosarcoma and tumors with smooth muscle cell-like differentiation: its specific expression in the smooth muscle cell tumor. Hum Pathol 1999; 30: 392-6.

28. Fletcher CDM, Cin PD, Wever I, et al. Correlation between clinicopathological features and karyotype in spindle cell sarcomas: a report of 
130 cases from the CHAP Study Group, Am J Pathol 1999; 154: 6.

29. Weiss SW. Smooth muscle tumors of soft tissue, advances in anatomic pathology. 2002; 9(6): 351-9.

30. Bautista N, Su W, O'Connel TX. Retroperitoneal soft tissue sarcomas: prognosis and treatment of primary and recurrent disease. Am J Surg 2000; 66: 832-6.

31. Erzen D, Sencar M, Novak J. Retroperitoneal sarcoma: 25 years of experience with aggressive surgical treatment at the Institute of Oncology, Ljubljana. J Surg Oncol 2005; 91: 1-9.

32. Ferrario T, Karakousis CP. Retroperitoneal sarcomas: grade and survival. Arch Surg 2003; 138: $248-51$.

33. Glenn J, Sindelar WF, Kinsella T, Glatstein E, Tepper J, Baker A, et al. Results of multimodality therapy of respectable soft tissue sarcomas of the retroperitoneum. Surgery 1985; 97: 316-24.

34. Baker CC, Gusberg RJ. Retroperitoneal soft tissue saromas: a continuing surgical callange. Conn Med 1986; 50: 217-20.

35. Storm FK, Mahvi DM. Diagnosis and management of retroperitoneal soft tissue sarcoma. Ann Surg 1991; 214: 2-10.

36. Jacques DP, Coit DG, Hajdu SI, Brennan MF. Management of primary and recurrent soft tissue of the retroperitoneum. 1990; 51-9.

37. Heslin JM, Lewis JL, Nadler E, Newman E, Woodruff JM, Casper ES, et al. Prognosis factors associated with long-term survival for retroperitoneum sarcoma: implications for management. J Clin Oncol 1997; 15: 2832-9.

38. Jones JJ, Catton CN, O'Sullivan B, Couture J, Heisler RL, Kandel RA, et al. Initial results of a trial of preoperative external beam radiation therapy and postoperative brachytherapy for retroperitoneal sarcoma. Ann Surg Oncol 2002; 9:

39. Mendenhall WM, Zoltecki RA, Hochwald SN, Hemming AW, Grobmyer SR, Cance WG. Retroperitoneal soft tissue sarcoma. Cancer 2005; 104: 669-75.

40. Svarvar C, Bohling T, Berlin O, Gustafs on P, Folleras G, Bjerkehagen B, et al. Clinical course of non-visceral soft tissue leiomyosarcoma in 225 patients from the Scandinavian Sarcoma Group. Cancer 2007; 109: 282-91.

41. Amdt C, Hawkins D, Anderson JR, Breitfled P, Womer R, Meyer W. Age is a risk factor for chemotherapy induced hepatopathy with vineristine, dactinomycin and cyclophosphamide. J Clin Oncol 2004; 22: 1894-1901.

42. Castex MP, Rubic H, Stevens MC, Escribano CC, de Gauzy JS, Gomez-Brouchet A, et al. Extra osseous localized ewing tumors improved outcome with anthracyclines - the French Society of Paediatric Oncology and International Society of Paediatric Oncology. J Clin Oncol 2007; 25: 1176-82.

43. Singer S, Cirsib JM, Demetri GD, Healey EA, Marcus K, Eberiein TJ. Prognostic factors predictive of survival for tunnel and retroperitoneal soft tissue sarcomas. Ann Surg 1995; 221: 185. 